\title{
ADOLF REINACH, NEGATIVE STATES OF AFFAIRS AND THE CONCEPT OF OMISSION
}

\begin{abstract}
This paper examines Adolf Reinach's views about negative states of affairs. The author briefly presents the history of the issue from the Middle Ages to the $20^{\text {th }}$ century. The views of Reinach and Roman Ingarden are compared. A special focus is ascribed to the problem of omissions in the legal sense. According to the author, a proper solution to the problem of negative states of affairs locates negation at the level of language, not in reality.
\end{abstract}

Keywords: negation, omissions, truth, semantics.

Adolf Reinach was not the first philosopher who observed troubles related to nelative states of affairs and tried to solve them (Reinach 1911). Roughly speaking, if $A$ is a negative sentence (proposition, statement, etc.), saying that $A$ refers to something ontologically negative appears to be a tempting idea. The issue bothered Aristotle and the Schoolmen, particularly with the respect to the concept of being. Here is a simplified argument (due mostly to medieval philosophers). Every general concept can be negated. Thus, if $C$ is a genus, non- $C$ arises by negation as a negative concept, for instance, we have ANIMAL and NON-ANIMAL (capitals without articles are used for making the further considerations more transparent). Moreover, if $C$ and non- $C$ are generic concepts, there exists a concept $D$ such that $C$ and non- $C$ are its species, for instance, both ANIMAL as well as NON-ANIMAL belong to the species ORGANIC CREATURE. The process from $D$ to $C$ and non- $C$ proceeds via determination, but generalization leads from $C$ and non- $C$ to $D$. So far, so good. However, consider the concept of being. If BEING is a concept, it has to have its negative counterpart, that is, NON-BEING, and, according to previous explanations, we should obtain a concept $D$ (BEING-NON-BEING) by generalization. However, it is impossible, because BEING acts as the most general concept which, as such, does not admit any generalization. The Schoolmen distinguished negatio and privatio as two different kinds of denial. The privation refers to a lack of something. Leaving aside, privations at the lower levels, NON-BEING does not refer to something existing, but expresses the lack of being something. The Schoolmen distinguished so-called transcendentalia, that is, the most general concepts. Their concrete

*University of Information, Technology and Management in Rzeszow, jan.wolenski@uj.edu.pl 
lists varied from one author to another, but BEING, TRUTH and GOODNESS populated every register of transcendentals. Thus, NON-BEING, NON-TRUTH (FALSEHOOD) and NON-GOODNESS (EVIL) consisted in lack of being, truth or goodness. Disregarding lower levels, for instance, illness as a lack of being healthy, at the top of the entire ontological hierarchy of genera (eventually with individuals as the lowest level), we have just privationes, not negative states of affairs. Yet it is a controversial issue whether the former have an objective being (existence) or belong to the mental realm.

Brentano pointed out another problem (see Brentano 1930, Chapter 1). Assume that we intend to elaborate the correspondence theory of truth as defined by the famous dictum (of Thomas Aquinus) veritas est adequatio rei et intellectus (I do not enter in the history of this idea going back to Aristotle; see Woleński 2019 for historical remarks). Thus, a sentence (or other bearer of truth, if chosen for a particular analysis, instance proposition, judgement, statement, thought, etc.) is true if and only if it corresponds with the reality. Consider the sentence

(1) London is not the capital of France.

This sentence is true. So it corresponds to reality, according to the main idea of the correspondence theory of truth. However, the reality (actuality) is a collection of positive facts (objects, states of affairs, situations, etc.) and, if so, there exists no fact consisting in London as not being the capital of France. Consequently, the correspondence theory of truth appears as essentially defective unless we accept negative states of affairs (perhaps as truth-makers, but I do not enter into this fairly complicated story). According to Brentano's philosophical views, any reasonable ontology should skip negative states of affairs from the ontological (or metaphysical) inventory.

The next example comes from jurisprudence. Criminal law distinguishes crimes of omission (see Clarke 2014 for an extensive analysis). Assume that $X$ working as a lineman did not close (omitted closing, abstaining from closing) the barrier at the crossroads of rail and a road. This situation resulted in a collision of a car and a train. The ordinary way of speaking admits to say that the collision in question became an effect of the omission in given circumstances. In other words, the fact that the lineman did not close the barrier caused the collision. However, it is an incorrect statement because omissions considered as negative states of affairs cannot stand in causal connections. The collision should be rather seen as an effect of the overcrossing of two physical processes, the movement of the train and the movement of the car. This argument was formulated by Professor Władysław Wolter, the professor of penal law at the Jagiellonian University - I heard this reasoning when I attended his course in the academic year 1959/1960. Some day in 1965, I travelled from Warszawa to Kraków by train. Because I was hungry, I went to the restaurant car, in which I joined Wolter and Roman Ingarden, my professor of philosophy. The former explained to the latter 
the problem of crimes of omission. Ingarden agreed that Wolter's account was correct. Ingarden formulated the issue in a very simple and impressive statement: "negative states of affairs have no causal powers, so omissions cannot be causes of anything". Wolter's argued that the lineman is responsible for a crime of omission not because of his abstaining from closing the barrier produced the collision as its effect, but according to the existence of a special legal obligation requiring a concrete action.

The previous discussion shows that the problem of negative states of affairs has not only historical aspects, but should be of interest for contemporary philosophers. Clearly, it has linguistic as well ontological dimension. The former concerns negative propositions, that is, having a form in which negation is explicitly or implicitly involved. Propositional calculus is the simplest logical theory in which negation as a connective occurs (I consider the classical system). Let $A$ be a sentence. So $\neg A$ is also sentence. Thus, the sign $\neg$ refers to a monadic propositional sentential functor having the truth-table: (a) if $A$ is true, $\neg A$ is false; (b) if $A$ is false, $\neg A$ is true. Clearly, $\neg A$ is more complex than $A$, because the former contains an additional symbol, assuming that no equivalent of negation occurs inside $A$. It is an interesting logical fact that typical logical sets of primitive logical notions in propositional calculus contain negation and something else, for example, implication, disjunction or conjunction (but not equivalence). Is it possible to define negation by a single different functor? The answer is "Yes". There are such functors, namely so-called the Sheffer constants. One of them has the table: (a) $A / B$ is false, if $A$ and $B$ are true; (b) $A / B$ is true in other cases. The negation can be defined by the formula $\neg A={ }^{\mathrm{df}} A / A$. We can say that $\neg$ occurs implicitly in $A / A$. The treatment of predicate negation is more complicated, because, for instance, the conditions for the equivalence of ' $a$ is not $P$ ' and $\neg(a$ is $P)$ or $\neg \exists x$ $A$ and $\forall x \neg A$ are more complex than in the propositional case, but proceed via exact syntactic and semantic rules. However, negation at the level of language is associated with regular linguistic structures.

The situation at the ontological level is different and dependent on an ontological theory. If one insists that no negative items occur in reality, he or she will try to eliminate negation, even implicit, from the ontological inventory. In other, words, everything that looks to be ontologically negative, must be replaced by positive properties, facts, states of affairs, etc. Admitting the ontological negation as something real, constitutes a serious philosophical decision, independently of its logical environment. Let me illustrate the interaction of logic and ontology by an example. Nothingness is a favourite metaphysical topic, even if we leave aside Heidegger's speculations on Das Nichts nichtet). Consider (I follow analysis in Twardowski 1894, 20; page-reference to English translation) the sentence 
(2) Nothing is eternal.

Apparently, (2) says something about the reference of the word "nothing" - this item is a good candidate of a negative state of affairs). However, we can replace (2) by

(3) There is no such $x$, such that $x$ is eternal.

The word "Nothing" was eliminated from (2) by the quantifier. More precisely (and using standard symbols, (3) can be written as

(4) $\neg \mathrm{G} x(x$ is eternal).

Twardowski's analysis shows that "Nothing" is not a name. On the other hand, the problem of the existence of negative states of affairs remains open. Although (4) can be considered as an assertion that no object is eternal, this analysis does not apply to all cases. Consider the sentence (i) " $a$ is not red", assuming that $a$ is yellow. Clearly, the sentence (ii) " $a$ is yellow" refers to a positive state of affairs and implies (i). Yet since (i) does not imply (ii), both these sentences are not equivalent. Accordingly, one can argue that (i) refers to a negative state of affairs, not reducible to a positive one. If the universe of properties is finite, let say, represented by the set $\left\{P_{1}, P_{2}, \ldots, \mathrm{P}_{\mathrm{n}}\right\}$, one should claim that the required equivalence is obtainable, but it essentially depends on a metaphysical assumption, perhaps correct in the case of colours, but not generally.

Although Reinach had predecessors in analysing negative states of affairs, his work (Reinach 1911; see historical comments in Smith 1982; Mulligan 1987; Dubois 1995; Reinach 1989, Teil 2) on this issue is perhaps the most complete attempt to copy with the problem. My task is to dress Reinach's proposals in more contemporary clothes (the previous discussion can be viewed as a background for my further remarks). Reinach considered the two dimensions related to the negative (this term is auxiliary), namely the linguistic and the ontological. The former concerns negative propositions, but the latter - negative states of affairs. These two dimensions are associated by Reinach according to the following preliminary thesis

(5) A proposition is an assertion (or denial) related to an objectual state of affairs.

Some comments on (5) are in order. Reinach as a faithful student of Husserl shared the anti-psychologism of his master. Thus, we can say that his propositions (Urteile in German) were conceived as qualified by the phrase "in the logical sense" and contrasted with propositions in the psychological understanding.

On the other hand, Reinach, similarly to other members of the phenomenological school, including Husserl himself, were bound (not uncritically, of course) by Brentano's philosophical horizon. The latter distinguished allogenic and idiogenic theories of propositions (judgments in the older terminology). The 
allogenic theory sees propositions as combinations of presentations or names, if we speak about linguistic entities (sentences, but the idiogenic conception considers propositions as sui generis entities. Reinach observed a problem associated with (2) consisting in how to answer whether assertion or denial are elements of propositions or their elements. Reinach explains the issue by the following example. Is a given flower red? We go to see the flower in question. If it is red, we are convinced that it is red (we believe in this - positive case, if not, e. g. if it is yellow, we disbelieve it (a negative); in this reasoning belief and disbelief are psychological entities. So, beliefs can be positive or negative (disbeliefs), and it depends on a position consisting in a relation to something else. This analysis of beliefs and disbeliefs analogically applies to propositions, particularly negative ones. Reinach maintains that the essence of negative propositions consists in their relation to negative states of affairs as their objectual correlates. This view is obviously contrary to Brentano's account of the correspondence theory.

Reinach's further analysis intends to explain why negative states of affairs are necessary for explaining the nature of negative judgments. One of his arguments consists in pointing out that relations between states of affairs are parallel to logical relations between propositions. Clearly, if negative propositions are not reducible to positive ones, the same concerns states of affairs. Consequently, according to Reinach, the propositions , $a$ is $b$ " and , $a$ is not $b$ " have similar character (both are affirmative) and have similar truth-conditions, that is, related to objective states of affairs (commands and questions are different). In the light of modern model-theoretic semantics, if $A$ and $\neg A$ are sentences, their truth-conditions are recursively given. Let me change notation somehow and write $+A$ for assertion of $A$ and $-A$ for denial of $A$. Clearly, the + and - express modi of $A$, as is required by the idiogenic theory of propositions. Frege's approach to sentences is perhaps the simplest account of the idea in question. Sentences have truth-values as their semantic references. All true sentences refer to the True and all false sentences - to the False. We have the only positive state of affairs, namely the True as well as the only negative state of affairs - the False. Yet we can correctly assert positive as well negative sentences - Frege's assertion sign - applies to both kinds of propositions. Reinach did not agree (he did not cite Frege in this context) that we have the only two "big" states of affairs, because he intended that the sentences "this flower is red" and "this flower is yellow" refer, assuming that both are true, to different ontological correlates, similarly as false sentences "London is not the capital of UK" and "Paris not the capital of France", and similarly, as true negative, for example "London is not the capital of France" and "Paris is not the capital of UK".

It will be instructive to compare Reinach and Ingarden. According to Ingarden (2016, §53), positive and negative states of affairs do not exist in the same way (note that Ingarden distinguished various kinds of existence, but I skip this issue). Take the sentence (*) " $a$ is $b$ " as true. The object $a$ exists autonomically and has 
a property $b$, but in the case of (**) " $a$ is not $b$ ", although $a$ really exists, $b$ is only in thought. Moreover, assume that $\left({ }^{*}\right)$ is true. If so, there is an unlimited number of states of affairs such of the type $(* * *)$ " $a$ is $c$ " such that (****) " $b$ is not $c$ ". And our initial statement, that (**) is true, if $a$ is $c$. This is essentially the argument outlined above, but take notice that the number of states of affairs falling under $(* * *)$ is unlimited. Ingarden (1925) employed in his analysis a distinction between the material and formal object of propositions going back to the Schoolmen. The former exist in reality, the latter are determined by the content (or sense) of propositions - they exist intentionally (I do not enter into details of Ingarden's theory of intentionality). Every proposition has a formal object, but material objects are associated with true propositions, In other words, both objects agree in the case of true propositions. According to Ingarden, only positive true propositions have states of affairs as their autonomous correlates - they have also formal objects generated by their senses, negative propositions have formal objects only. Incidentally, it is interesting to see that Reinach and Ingarden, both representing realistic phenomenology, differed so much in their ontology, particularly in their approach to negative states of affairs.

Now I return to the problem of omission. Once again, Wolter pointed out (see above) that the lineman is responsible not for causing the collision, but because he omitted an obligatory action, because negative states of affairs have no causal powers. Wolter argued that a great number of people did not close the barrier but he denied that they committed a crime of omission. I simplify, because I disregard the situation in which a "neutral" person should react confronted with a danger, for instance, a person can see that a train approaches, but the barrier is not closed. The lineman can also be excused in some circumstances, for example, if he cannot act as is excused in some circumstances, for example, because he limited physical ability to act in the required manner. Anyway, we have a clear message that omission is something more than not-doing. For Wolter, omission is a directional not-doing. How are we to analyse this category in a more formal (logical) way?

In order elaborate $t$ at least partially the last question, I will employ a simple device, that is, the logical square (LS, for brevity) for action sentences (see Woleński, 2008 for a detailed presentation) for a more detailed account:

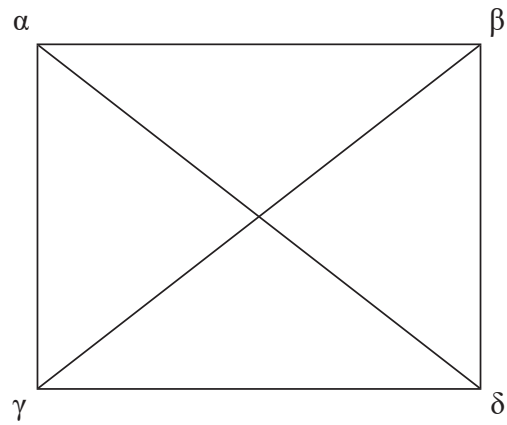


Interpret $\alpha$ as " $X$ did so that $A$ ", $\beta$ as " $X$ did so that $\neg A$ ( $X \operatorname{did}$ not- $A$ ), $\gamma$ as "It is not so that $X$ did not- $A, \delta$ as "It is not so, that $X \operatorname{did} A$. We have well known relations summarized in the following list:

(6) (a) $\alpha \rightarrow \gamma$;

(b) $\beta \rightarrow \delta$;

(c) $\neg(\gamma \rightarrow \alpha)$;

(d) $\neg(\delta \rightarrow \beta)$;

(e) $\neg(\alpha \wedge \beta)$ ( $\alpha$ and $\beta$ are contrary; both cannot be true);

(f) $\gamma \vee \delta$ ( $\gamma$ and $\delta$ are subcontrary); both cannot be false);

(g) $\neg(\alpha \leftrightarrow \delta)$ ( $\alpha$ and $\delta$ are contradictory);

(h) $\neg(\gamma \leftrightarrow \beta)$ ( $\gamma$ and $\beta$ are contradictory).

The points (6b) and (6d) are the most essential for our topic. Since (see (6d) doing not implies not doing, but not conversely (see (6d), the former (doing not) is essentially stronger than the latter (not doing). Hence, doing not is something more than not doing. Unfortunately, the qualification "more" functions here as a metaphor. Since this linguistic figure apparently goes beyond logic, it requires further explanations.

At first glance, it is tempting to identify "it is so that $X$ omits that $A$ (abstains from doing $A$ " with "it is so that $X$ does not- $A$ ". However, adopting this equivalence does not adequately reproduces Wolter's position, because it ignores the factor of being directed involved in doing that not- $A$ (this factor is just responsible that doing not- $A$ is "more" than not-doing $A$; see the last paragraph). Since the intention (as behaving purposively in a way) of the lineman in his course of his action is not relevant for omission, we cannot say that his desire of not-doing is enough for omission. In fact, crimes of omission can be performed by so-called dolus eventualis, that is, in such a way that $X$ should act in a prescribed way, but he or she abstained from the action in question. Thus, the lineman cannot excuse himself by saying "I am sorry, but I did not desire to cause the catastrophe in question". It is not inconsistent with Brentano's thesis that every mental is intentional in the sense that it is directed to some object. Even if the lineman is conscious that the train approaches and this state of affairs is the intentional object of his thinking (I skip the difficult problem of the nature of intentional objects), this fact does not matter in his abstaining of the required action. Consequently, "directed" understood in Wolter's sense is at last partially different from being directed as intentional. Reinach would perhaps say that the negative statement not- $A$ refers to a negative state of affairs as its ontological (objectual) correlates. On his analysis, accepting that such entities exist appears as indispensable for a reasonable theory of truth conditions for action sentences asserting abstaining from doing something as well as other negative propositional utterances. However, ontology as such cannot offer a complete theory of omissions, even if we agree with Ingarden that negative states of affairs have no causal powers. Wolter's approach offers a hint, but it is 
still unclear of how "more" in omissions should be interpreted, psychologically or in some other way.

The idiogenic theory of propositions, shared by Reinach, offers some prospects for a general account of action sentences. It is convenient to combine Reinach's ideas with some of Twardowski's views. According to the latter (see Twardowski 1894), every propositions has a moment, content and object. Twardowski identified moment and the character of an act, for instance asserting is a moment of an act of making an assertion. But this idea can be generalized in a way. If we consider a concrete propositional content expressed by $A$, it might have various moments also in the case of propositions related to actions. Take the proposition that the lineman did not close the barrier. It has a hidden moment (modus) "he did so", but also the normative moment qualifying the action in question as obligatory - moments of permission or prohibition occur in other normative contents. Reinach developed the idea of performatives (social acts; Reinach 1913) that is utterances creating something by using of words. He applied this idea mostly to promises arguing that a promise creates a special (normative?) state of affairs. Generalizing this ides, it is possible to say that issuing a norm "the lineman has the obligation to close the barrier" creates an explicit duty directed to the lineman, not to other persons, unless other legal provisos exist and impose obligation of other agents. Consequently, we can say that this norm creates a duty of performing an action and prohibits violating this obligation.

We have two possibilities to interpret this situation:

(A) Not doing something which is obligatory constitutes a negative state of affairs; a problem is that we need to enrich ontology by negative normative states of affairs - so we have normative negative states of affairs and non-normative ones;

(B) We have only positive states of affairs, but omission is a conscious (directional in Wolter's sense); note comments above) non-doing, consisting in doing something what excludes fulfilment of duty.

Adopting (B) can be motivated by the claim that doing and doing not should be considered in a symmetric way. Hence, assuming that doing contains an intention (with noticing the problem of dolus eventualis), the same concerns doing not expressed by the locution " $X$ did so that not $A$ ". As far as the issue concerns the latter, the moment indicated by the phrase "did so that" imposes an intentional (as well as semantic) factor on a state of affairs as somehow derivative of doing something else than $A$. Although there are several philosophical problems of this way of speaking, we have a route to dispense with negative states of affairs as existing in the same way as positive ones. In other words, semantics via possible worlds as objects in which propositions are true or false does not require negative states of affairs. On the other hand, these classes are derivative of social acts, at least in the case of normative regulations. Semantically speaking, Reinach's theory 
of social acts (similarly as Austin's conceptions of performatives) is to be applied without approving negative states of affairs as independent ontological items.

On my part, I am inclined to reject negative states of affairs as actual. This view can be supported by model-theoretic semantics. If we state truth-conditions for negative sentences (see above), any appeal to ontological negative is redundant. This means that negation is in language, not in reality. Although logical semantics does not solve the controversy over negative states of affairs, it provides a hint seeing the issue in a perspective. Returning to the points (6b) and (6d) as logical dependencies generated by $\mathbf{L S}$, they can be regarded as formulations of necessary formal conditions for a correct analysis of omission, but, and it should be stressed, they do not form a sufficient condition. In general, a full analysis of omissions exceeds the scope of logic. On the other hand, the analysis of such items via logical tools (in this case provided by LS) constitutes a good example of considerations deserved to be called formal ontology. In others words, I consider formal logical ontology as a particularly promising fragment of philosophical reflection. To be modest, it is only the first word, not the last one.

\section{BIBLIOGRAPHY}

Brentano, Franz. 1930. Wahrheit und Evidenz. Hamburg: Meiner.

Brentano, Franz. 1971. The True and the Evident. Edited by Oskar Kraus. Translated by Roderick M. Chisholm, Ilse Politzer, Kart R. Fischer. London: Routledge and Kegan Paul.

Clarke, Rudolph. 2014. Omissions. Agency, Metaphysics, and Responsibility. Oxford: Oxford University Press.

Dubois, James. M. 1995. Judgment and Sachverhalt. An Introduction of Adolf Reinach's Realistic Phenomenology. Dordrecht: Kluwer.

Ingarden, Roman. 1925. "Essentiale Fragen. Ein Beitrag zum Wesensproblem". Jahrbuch für Philosophie und philosophische Forschung 7: 125-304.

Ingarden, Roman. 1948. Spór o istnienie świata. Tom II. Ontologia formalna. Część 1. Forma i istota. Kraków: PAU.

Ingarden, Roman. 2016. The Controversy over the Existence of the World. Vol. II. Translated by Arthur Szylewicz. Frankfurt: Peter Lang.

Mullligan, Kevin. Ed. 1987. Speech Act and Sachverhalt. Reinach and the Foundations of Realistic Phenomenology. The Hague: Nijhoff.

Reinach, Adolf. 1911. "Theorie des negativen Urteils". In Münchener Philosophische Abhandlungen. 196-254. Edited by Alexander Pfänder. Leipzig: Barth.

Reinach, Adolf. 1913. "Die apriorischen Grundlagen der bürgerlichen Rechtes". Jahrbuch für Philosophie und philosophische Forschung 1: 685-847.

Reinach, Adolf. 1989. Sämtiliche Werke. Textkritische Ausgabe 1. Werke. 2. Kommentar und Textkritik. Edited by Karl Schuhmann, Barry Smith. München: Philosophia Verlag.

Smith, Barry. 1982. "Introduction to Adolf Reinach: On the Theory of the Negative Judgment". In Parts and Moments. Studies in Logic and Formal Ontology. 289-313. Edited by Barry Smith. München: Philosophia Verlag.

Smith, Barry. Ed. 1982. Parts and Moments. Studies in Logic and Formal Ontology. München: Philosophia Verlag. 
Twardowski, Kazimierz. 1894. Zur Lehre vom Inhalt und Gegenstand der Vorstellungen. Wien: Hölder.

Twardowski, Kazimierz. 1977. On the Content and Object of Presentation. A Psychological Investigation. Translated by Reinhardt Grossmann. The Hague: Martinus Nijhoff.

Woleński, Jan. 2008. "Applications of Squares of Oppositions and Their Generalizations in Philosophical Analysis". Logica Universalis 2(1): 13-29.

Woleński, Jan. 2011. "Applications of Squares of Oppositions and Their Generalizations in Philosophical Analysis”. In Essays on Logic and Its Applications in Philosophy. 255-269. Frankfurt: Peter Lang. [Reprint]

Woleński, Jan. 2019. Semantics and Truth. Berlin: Springer. 